\title{
Patient perspectives on the use of digital health services at a multi-site hospital in North-West London: a quantitative content analysis
}

Jackie van Dael, Ana Luisa Neves, Annabelle Painter, Patrick Bachtiger, Niki O'Brien, Clarissa Gardner, Jennifer K Quint, Alex Adamson, Nicholas S Peters, Ara Darzi, Saira Ghafur

Submitted to: Journal of Medical Internet Research on: March 08, 2021

Disclaimer: () The authors. All rights reserved. This is a privileged document currently under peer-review/community review. Authors have provided JMIR Publications with an exclusive license to publish this preprint on it's website for review purposes only. While the final peer-reviewed paper may be licensed under a CC BY license on publication, at this stage authors and publisher expressively prohibit redistribution of this draft paper other than for review purposes. 


\section{Table of Contents}

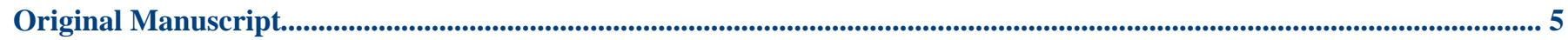

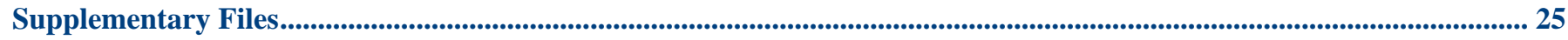

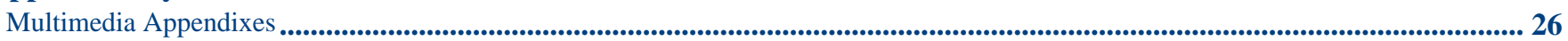

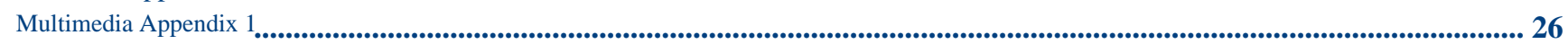




\section{Patient perspectives on the use of digital health services at a multi-site hospital in North-West London: a quantitative content analysis}

Jackie van Dael ${ }^{1}$; Ana Luisa Neves ${ }^{2,3}$ MSc, PhD, MD; Annabelle Painter ${ }^{4}$; Patrick Bachtiger ${ }^{5}$; Niki O'Brien ${ }^{6}$; Clarissa Gardner $^{6}$; Jennifer K Quint ${ }^{5}$ MSc, PhD, FHEA, FRCP; Alex Adamson ${ }^{5}$; Nicholas S Peters ${ }^{5}$ MD, FRCP; Ara Darzi ${ }^{6}$ FREng, FMedSci, FRS, PC, KBE, OM; Saira Ghafur ${ }^{6}$ MSc, MRCP, MBChB

\footnotetext{
${ }^{1}$ University of Porto Porto PT

${ }^{2}$ NIHR Imperial Patent Safety Translational Research Centre Imperial College London London GB

${ }^{3}$ Imperial College Healthcare NHS Trust London GB

${ }^{4}$ National Heart and Lung Institute Imperial College London London GB

${ }^{5}$ Institute of Global Health Innovation Imperial College London London GB
}

\section{Corresponding Author:}

Jackie van Dael

\section{Abstract}

Background: Following a large increase in the adoption of digital health amidst the COVID-19 crisis, there is increasing policy interest in the longer-term implementation of digital health services. Yet, there is still much unknown about the inherent quality of remote digital care, and research on patient perspectives remains comparatively small. Widespread usage amidst COVID-19 presents an important opportunity to better understand patients' first-hand experiences with using these technologies.

Objective: This study examined patients' perspectives on main benefits and concerns with using digital health services in a large multi-site teaching hospital in North-West London during the COVID-19 crisis.

Methods: Qualitative data was obtained from a larger questionnaire conducted during the COVID-19 pandemic on Care Information Exchange, which represents the largest patient-facing electronic health records in the English National Health Service. All responses were analysed using the framework analysis method. Quantitative content analysis was performed by mapping frequencies of reported themes across the respondent population.

Results: Of all 6,766 respondents, $25.1 \%$ reported to have no concerns with digital health services, compared to $3.0 \%$ reporting no benefits. Reported benefits included: ease of access (37.1\%), feeling empowered and informed (23.2\%), improved timeliness of access and treatment (18.6\%), healthcare capacity (11.5\%), and care continuity amidst COVID-19 (7.4\%). In contrast, reported concerns included issues around data security and privacy (17.5\%), clinical uncertainty (17.0\%), impact on patientdoctor relationship (11.9\%), inequity in access and use (11.8\%), misunderstanding health information (6.3\%), and digital maturity $(3.8 \%)$.

Conclusions: Patients report many benefits with digital health services beyond immediate COVID-19 support, including improved access, timeliness, and enhanced healthcare capacity. Yet, some concerns remain, including some less-addressed problems such as the more fundamental impacts on clinical effectiveness and the patient-doctor relationship. These large-scale and patient-driven insights can inform main areas to be addressed in future research and practice.

(JMIR Preprints 08/03/2021:28603)

DOI: https://doi.org/10.2196/preprints.28603

\section{Preprint Settings}

1) Would you like to publish your submitted manuscript as preprint?

$\checkmark$ Please make my preprint PDF available to anyone at any time (recommended).

Please make my preprint PDF available only to logged-in users; I understand that my title and abstract will remain visible to all users.

Only make the preprint title and abstract visible.

No, I do not wish to publish my submitted manuscript as a preprint.

2) If accepted for publication in a JMIR journal, would you like the PDF to be visible to the public? 
$\checkmark$ Yes, please make my accepted manuscript PDF available to anyone at any time (Recommended).

Yes, but please make my accepted manuscript PDF available only to logged-in users; I understand that the title and abstract will remain $v$ Yes, but only make the title and abstract visible (see Important note, above). I understand that if I later pay to participate in <a href="http 


\section{Original Manuscript}




\title{
Original Paper
}

\section{Patient perspectives on the use of digital health services at a multi-site hospital in North-West London: a quantitative content analysis}

\begin{abstract}
Background: Following a large increase in the adoption of digital health amidst the COVID-19 crisis, there is increasing policy interest in the longer-term implementation of digital health services. Yet, there is still much unknown about the inherent quality of remote digital care, and research on patient perspectives remains comparatively small. Widespread usage amidst COVID-19 presents an important opportunity to better understand patients' first-hand experiences with using these technologies.
\end{abstract}

Objective: This study examined patients' perspectives on main benefits and concerns with using digital health services in a large multi-site teaching hospital in North-West London during the COVID-19 crisis.

Methods: Qualitative data was obtained from a larger questionnaire conducted during the COVID19 pandemic on Care Information Exchange, which represents the largest patient-facing electronic health records in the English National Health Service. All responses were analysed using the framework analysis method. Quantitative content analysis was performed by mapping frequencies of reported themes across the respondent population.

Results: Of all 6,766 respondents, 25.1\% reported to have no concerns with digital health services, compared to 3.0\% reporting no benefits. Reported benefits included: ease of access (37.1\%), feeling empowered and informed (23.2\%), improved timeliness of access and treatment (18.6\%), healthcare capacity (11.5\%), and care continuity amidst COVID-19 (7.4\%). In contrast, reported concerns included issues around data security and privacy (17.5\%), clinical uncertainty (17.0\%), impact on patient-doctor relationship (11.9\%), inequity in access and use (11.8\%), misunderstanding health information (6.3\%), and digital maturity (3.8\%).

Conclusions: Patients report many benefits with digital health services beyond immediate COVID19 support, including improved access, timeliness, and enhanced healthcare capacity. Yet, some concerns remain, including some less-addressed problems such as the more fundamental impacts on clinical effectiveness and the patient-doctor relationship. These large-scale and patient-driven insights can inform main areas to be addressed in future research and practice.

Keywords: Telemedicine; COVID-19; patient-centred care; secondary care; framework analysis; health systems; National Health Service; patient-physician relationship

\section{Introduction}

The COVID-19 pandemic has accelerated the long-awaited digital transformation of healthcare[1]. Amidst home-quarantine, social distancing and an increased burden on the healthcare system, remote 
digital care (or: 'telemedicine'[2]) has become an immediate reality for many, allowing patients to access or continue their care, and seek help for deterioration at home[3,4]. In the USA, it was announced that Medicare will now cover at least part of telemedicine services[5], while the National Health Service (NHS) in the UK has rolled out Attend Anywhere[6], a secure NHS video call service for patients with pre-arranged appointments. This is in sharp contrast with outpatient care delivery before the pandemic, where only a minor proportion of consults were held via remote modes[7].

This rapid shift has removed some long-standing barriers to adoption (e.g. interoperability[8], resistance to change[9]), and has resulted in wide-spread interest to increasingly integrate digital health services into our 'new normal'. Telemedicine, which includes a range of digital health solutions such as remote consultations, personal health records, and mobile health apps, has been associated with a range of benefits. In secondary care (which represents $85 \%$ of hospital-based activity in the UK[10]), there is tentative evidence to suggest increased delivery of video-based outpatient consultations can reduce the need for face-to-face appointments for simple and routine check-ups[11,12], waiting times[13], and costs for patients[14] (e.g. travel). Similarly, a range of studies have shown that personal health records and mobile health apps can support effective selfmanagement, including improved medication adherence[15,16] and chronic disease management (e.g. asthma; diabetes)[17-19].

However, despite these potential benefits, there is still much unknown about the inherent quality of telemedicine solutions, and how the transformation to remote digital care has impacted on patients' experiences of the healthcare system. Although the past decades have seen a growing number of studies on clinicians' views and experiences, the equivalent body of research on patient perspectives remains comparatively small, particularly in secondary care. Critical digital health studies have raised concerns around the more fundamental social, cultural, and political impacts of the digital health 'revolution'[20], such as citizen surveillance[21-23], self-tracking[24-26], and the patientdoctor relationship[27]. Other research has raised concerns around potential harms and risks of patient self-service use of health apps, such as increased anxiety[28] and the limited quality assurance that exists in some areas (e.g. non-validated mental health apps)[29-31].

Hence, following the large increase in the adoption of digital remote care amidst the COVID-19 crisis, and subsequent policy interest in longer term implementation, there is a clear need to better understand patients’ first-hand experiences with using digital health services. 


\section{Aim of this study}

This study will examine patients' descriptions of main benefits and concerns with using digital health services in secondary care during the COVID-19 crisis. Through analysing and codifying 6,766 freetext survey responses, results will provide large-scale and patient-driven insight on main areas to be addressed in future research and practice.

\section{Methods}

\section{Questionnaire Design}

This study uses qualitative data from a larger questionnaire conducted as part of The Longitudinal Effects on Wellbeing of the Covid-19 Pandemic (LoC-19) project in August 2020. This project hosts weekly questionnaires on Care Information Exchange (CIE) at a large multi-site teaching hospital in North-West London, which represents NHS' largest patient-facing electronic health record. An invitation to complete the questionnaire was shared with all CIE registrants who previously opted-in to receive weekly questionnaire invites for the LoC-19 project $(n=18,581)$. A total of 9,359 of all 18,581 invited participants completed the survey (50.4\%), of which 6,766 (72.3\%) provided answers to both or either of the two free-text questions and were included in this study.

The two open-ended questions in this survey queried perceived benefits and concerns on a range of digital health services, including remote consultations, personal health records, health apps, on-line symptom checkers, and health websites. Beyond the two items included in this study, the original survey was made-up of a range of multiple-choice questions, developed by a multi-disciplinary team of researchers (SG; ALN; CG; PB; NSP). Survey items were tested with patient and carer representatives $(n=5)$ before being included in the final questionnaire. A full version of the original questionnaire can be found in Multimedia Appendix 1.

\section{Coding strategy}

Three researchers (JD; CG; NB) analysed the free-text responses using the framework analysis method[32]. This method was considered appropriate in this study due to its propensity to analyze large qualitative datasets in a systematic manner[33]. Framework analysis involves five stages: data familiarization, developing a thematic framework, indexing, charting, mapping, and interpretation[33]. Two researchers (JD; CG) independently re-read a sub-set of the dataset $(\mathrm{n}=$ 
2,000, 29.6\%) Based on this, each researcher developed a list of initial codes in an inductive manner. A meeting was facilitated by a third researcher (ALN) to review, discuss, and revise initial codes towards an agreed set of codes which were then organized into overarching domains. This provided a working coding framework which was applied by two researchers (JD; AP) who each coded half of the dataset. The coding framework was adjusted iteratively throughout the analysis stage to ensure no critical codes (e.g., frequently occurring, or distinctive themes) were missed. Once finalized, a third researcher (NB) coded a randomised sub-set of 900 responses (13.3\%) to test inter-rater reliability in applying the framework.

\section{Inter-rater reliability}

Inter-rater reliability was tested using Gwet's AC1[34,35], which corrects for category distribution. Average AC1 for codifying domains was 0.87 (range 0.72-0.98) for benefits and 0.93 (range 0.860.99) for concerns, indicating excellent agreement[36].

\section{Quantitative Analysis}

Frequencies of reported themes across the respondent population were reported using descriptive statistics (frequencies). Analyses were conducted in Stata version 13 (StataCorp LLC).

\section{Results}

\section{Respondent Characteristics}

A total of 6,766 individuals responded to the free-text survey items included in this study. Table 1 summarised the demographic characteristics of the respondents.

Table 1. Characteristics of the respondent population $(n=6,766)$

\begin{tabular}{|l|l|}
\hline Variable & $\boldsymbol{n}(\mathbf{\%})$ \\
\hline Age & \\
\hline $18-24$ & $50(0.8)$ \\
\hline $25-34$ & $394(5.8)$ \\
\hline $35-44$ & $766(11.3)$ \\
\hline $45-54$ & $1,197(17.7)$ \\
\hline $55-64$ & $1,827(27.0)$ \\
\hline $65-74$ & $1,819(26.9)$ \\
\hline $75+$ & $131(1.9)$ \\
\hline & \\
\hline Gender & \\
\hline Female & $3,905(57.7)$ \\
\hline Male & $2,861(42.3)$ \\
\hline
\end{tabular}




\begin{tabular}{|l|l|}
\hline & \\
\hline Ethnicity & \\
\hline Asian / Asian British & $382(5.6)$ \\
\hline Black / African / Caribbean / Black British & $214(3.2)$ \\
\hline Mixed / Multiple Ethnic Groups & $123(1.8)$ \\
\hline Other Ethnic Group & $137(2.0)$ \\
\hline White & $4,925(72.8)$ \\
\hline Other or prefer not to say & $985(14.6)$ \\
\hline
\end{tabular}

\section{Patient Perspectives on Digital Health Technologies}

Respondents reported a mean of 1.5 benefits $(S D=0.5)$ and a mean of 1.1 concerns $(S D=0.3)$. Out of all 6,766 responses, 3.0\% reported that they did not see any benefits versus $25.1 \%$ reporting no concerns. Benefits and concerns were mostly discussed in the context of remote consultations and personal health records. The use of health apps, on-line symptom checkers, and health websites were discussed to a lesser degree, and mostly pertained to the themes "patient empowerment" (benefit) and “(mis)understanding information” (concern).

\section{Patient-reported benefits with digital health technologies}

Table 2 summarizes main benefits reported by respondents, their respective frequency (mentioned in ...\% of responses), and example quotes. Responses were classified into five domains: ease of access (37.1\%); being empowered and informed (23.2\%); timeliness of care (18.6\%); healthcare efficiency and resources (11.5\%); and care continuity amidst COVID-19 (7.4\%). Out of all 6,766 responses, 3.0\% reported that they did not see any benefits; 3.1\% did not respond to this survey item; and $16.8 \%$ provided insufficient information to codify or did not fit into the coding framework.

Responses classified as ease of access reported benefits with regards to reduced time and costs (e.g. travel; taking time off; childcare), widened access (e.g. for patients with mobility issues; no need to travel while ill), and enhanced flexibility (e.g. accessing care when and where desired). This theme was often mentioned in the context of minor outpatient appointments and simple check-ups. In terms of empowered and informed, many felt that accessing personal health records had enable them to be informed and manage their healthcare, for example by keeping track of appointments, reviewing test and scan results, and accessing information to prepare for upcoming consultations. The use of mHealth apps for self-managing and improving health was also reported by several respondents. Descriptions of timeliness of care described receiving faster access to remote consultations (compared to face-to-face), quicker prescriptions and referrals, and the benefit of immediate self-help 
information through on-line symptom checkers and health information websites. Those reporting care continuity amidst COVID19 referred to the ability to continue care while stay at home and not endanger oneself, peer patients, or healthcare workers. Patients who discussed healthcare capacity felt that consultations and digital triaging were more time-efficient, had the potential to reduce number of patients missing appointments (e.g. due to travel delays), and would help minimize unnecessary provider resources spent on minor problems or simple check-ups.

Table 2. Reported benefits with digital healthcare solutions across responses $(n=6,766)^{\mathrm{a}}$

\begin{tabular}{|c|c|c|}
\hline Theme & $n(\%)$ & Example quote \\
\hline $\begin{array}{ll}\text { Ease } & \text { of } \\
\text { access } & \end{array}$ & $\begin{array}{l}2,508 \\
(37.1)\end{array}$ & $\begin{array}{l}\text { "It makes tending to my healthcare easier - mainly because it's far less } \\
\text { time consuming due to not travelling. I also have children so } \\
\text { appointments don't have to be made around their schedules." } \\
\text { "It is very hard for me to attend appointments and my daughter, who is } \\
\text { also my registered carer, works full time. It is easier to not go in person } \\
\text { for everything. Phone consultations and online access/information } \\
\text { sharing where possible is much easier" }\end{array}$ \\
\hline $\begin{array}{l}\text { Feeling } \\
\text { empowered } \\
\text { and } \\
\text { informed }\end{array}$ & $\begin{array}{l}1,567 \\
(23.2)\end{array}$ & $\begin{array}{l}\text { "The pandemic forced the innovations in virtual care to happen, I had } \\
\text { never before had access to Patient Knows Best or DrDr and it happened } \\
\text { quickly due to the pandemic. Benefits are immense, allowing me to own } \\
\text { my care and understand my clinical data and be part of my plan of care." } \\
\text { "Empowers one to be proactive in with health and gives them } \\
\text { knowledge which can allay uncertainty and then allow for self-care." }\end{array}$ \\
\hline $\begin{array}{l}\text { Timeliness } \\
\text { of care }\end{array}$ & $\begin{array}{l}1,259 \\
(18.6)\end{array}$ & $\begin{array}{l}\text { "The introduction of these digital technologies during the pandemic has } \\
\text { been great. It has allowed patients to access care quicker and faster. It } \\
\text { has also allowed patients to contact their named consultant or medical } \\
\text { healthcare professionals as I when they have felt it was necessary. It has } \\
\text { also meant that patients have not had to wait too long for follow } \\
\text { up/review appointments, like they normally would have before the } \\
\text { pandemic." } \\
\text { "Removes the "wall" from primary care no need for appointments. E.g. I } \\
\text { do not need to wait a long time on the phone to request a repeat blood } \\
\text { form or make an appointment to request one!" }\end{array}$ \\
\hline $\begin{array}{l}\text { Healthcare } \\
\text { quality }\end{array}$ & $\begin{array}{l}778 \\
(11.5)\end{array}$ & $\begin{array}{l}\text { "Freeing up the time of clinicians to see face to face those patients who } \\
\text { really need to be seen as opposed to, for example, having to attend a } \\
\text { clinic simply to talk about test results." } \\
\text { "They allow medical practitioners to have more time for severe and } \\
\text { urgent cases" }\end{array}$ \\
\hline Care & 503 & "COVID-19 brought feelings of isolation, fear of attending medical \\
\hline
\end{tabular}




\begin{tabular}{|l|l|l|}
\hline $\begin{array}{l}\text { Continuity } \\
\text { amidst } \\
\text { COVID-19 }\end{array}$ & $\mathbf{( 7 . 4 )}$ & $\begin{array}{l}\text { facilities etc. By using this tech, I still felt fully supported by the clinics } \\
\text { I usually attended." }\end{array}$ \\
& $\begin{array}{l}\text { "Zoom sessions provide ongoing sessions without risking catching } \\
\text { COVID-19 either in the crowded class room or on public transport." }\end{array}$ \\
\hline
\end{tabular}

${ }^{a}$ Of all 6,766 responses, 202 (3.0\%) respondents reported "no benefits"; 1,140 (16.8\%) responses were classified as "unspecified or other”; 211 (3.1\%) did not respond to this survey item.

Responses classified as "unspecified or other" included insufficient information for meaningful codification (e.g. "they are great”; “do not know"; "the way forward”) or did not relate to a specific theme. It was often noted that remote consultations were beneficial in some cases, but not all (e.g. "very useful in the right circumstances"; "good for minor issues”).

\section{Patient-reported concerns with digital health technologies}

Table 3 summarizes main concerns reported by respondents, their respective frequency (mentioned in ...\% of responses), and example quotes. Responses were classified into six domains: data security and privacy (17.5\%); clinical uncertainty (17.0\%); patient-doctor relationship (11.9\%); inequity of access and use (11.8\%); (mis)understanding information (6.4\%); and digital maturity (3.8\%). Out of all 6,766 responses, 25.1\% reported no concerns; 4.8\% did not respond to this survey item; and 9.6\% provided insufficient information to codify or did not fit into the coding framework.

Responses classified as data security and privacy reported concerns with cybersecurity and data being shared with the government and other third parties. In terms of clinical uncertainty, many felt that there was a higher risk of misdiagnosis due to the absence of palpation and increased likelihood of missed information and misunderstandings when communicating virtually. Others noted that they found it hard to explain symptoms verbally (i.e. over a physical examination). Concerns with impact on the patient-doctor relationship referred to the absence of interpersonal reassurance, missing the human connection with clinicians and the wider care team, and a perceived reduction of holistic care. Regarding inequity in access and use, respondents noted the risk of excluding patients due to limited access to WIFI or digital devices, language barriers, and low digital literacy. Responses discussing digital maturity referred to the limited quality of existing health technologies, worry about artificial intelligence (AI) bias and tech glitches, and inadequate preparedness of the IT infrastructure in the NHS. Others noted the difficulty of understanding data and information within health records or mobile apps, the danger of incorrect self-diagnosis, and subsequent anxiety caused. 
Table 3. Reported concerns with digital healthcare solutions across responses $(n=6,766)^{\mathrm{a}}$

\begin{tabular}{|c|c|c|}
\hline Theme & $n(\%)$ & Example quote \\
\hline $\begin{array}{l}\text { Data } \\
\text { security } \\
\text { and } \\
\text { privacy }\end{array}$ & $\begin{array}{l}1,183 \\
(17.5)\end{array}$ & $\begin{array}{l}\text { "I'm happy to use these technologies but I think you need to be very } \\
\text { mindful of privacy, data security, and strictly limiting who has access to } \\
\text { personal / health data." } \\
\text { "Data hacks and government knowing too much about me. Also potential } \\
\text { selling of this data - insurance companies would not provide cover if they } \\
\text { knew you had pre-existing conditions and there should be no bias." }\end{array}$ \\
\hline $\begin{array}{l}\text { al } \\
\text { ainty }\end{array}$ & $\begin{array}{l}1,151 \\
(17.0)\end{array}$ & $\begin{array}{l}\text { "The nagging doubt that the patient has not been seen "properly". The } \\
\text { clinician cannot use their sense of touch, for example. Or the clinician } \\
\text { may notice something from the patient's appearance or manner. Or the } \\
\text { opportunity is missed to take a blood-pressure or temperature reading." } \\
\text { "Assuming the pandemic ends one day, I can't see how talking to a doctor } \\
\text { via video link for a potential new health problem can be as effective as } \\
\text { meeting face-to-face. Physical examination, body language, proper } \\
\text { communication are all better in person than via video or phone." }\end{array}$ \\
\hline $\begin{array}{l}\text { Patient- } \\
\text { doctor } \\
\text { relationshi } \\
\text { p }\end{array}$ & $\begin{array}{l}807 \\
(11.9)\end{array}$ & $\begin{array}{l}\text { "There is no substitute for a face-to-face meeting with a doctor. A patient } \\
\text { is more than just an ailment. They may feel alienated or unwanted by the } \\
\text { health professional on the other end. The best experience a person can } \\
\text { have is to have proper relationship with their doctor, GP practice or } \\
\text { hospital personnel." } \\
\text { "Nothing beats a face-to-face contact with a health care professional. } \\
\text { Technology has its uses but it can never replace a human empathetic voice } \\
\text { or caring attitude." }\end{array}$ \\
\hline $\begin{array}{l}\text { Inequity of } \\
\text { access and } \\
\text { use }\end{array}$ & $\begin{array}{l}796 \\
(11.8)\end{array}$ & $\begin{array}{l}\text { "My concern is that older people could be left out or feel threatened by } \\
\text { technologies. I have limited sight and wonder how I'd cope if my vision } \\
\text { deteriorates even more." } \\
\text { "We often have a bad internet connection in our house, and mobile phone } \\
\text { reception is practically non-existent." }\end{array}$ \\
\hline $\begin{array}{l}\text { (Mis)under } \\
\text { standing } \\
\text { informatio } \\
\text { n }\end{array}$ & $\begin{array}{l}431 \\
(6.4)\end{array}$ & $\begin{array}{l}\text { "Being able to access test results is right and proper in principle, but lack } \\
\text { of own medical knowledge can mean either worrying about something } \\
\text { which doesn't matter, or alternatively not realising the potential } \\
\text { seriousness of a result." } \\
\text { "I have received test results that have caused me fear and anxiety, as I } \\
\text { have not had anyone to discuss them with on receipt and may well be } \\
\text { misinterpreting them but may not." }\end{array}$ \\
\hline & $\begin{array}{l}258 \\
(3.8)\end{array}$ & $\begin{array}{l}\text { IS technology not being good enough for them to work effective } \\
\text { up with in-person care notes" }\end{array}$ \\
\hline
\end{tabular}




\begin{tabular}{|l|l|l|}
\hline & $\begin{array}{l}\text { "I tried to use NHS } 111 \text { but they came up with wrong answer because it } \\
\text { [the algorithm] couldn't understand the question I had." }\end{array}$ \\
\hline
\end{tabular}

${ }^{a}$ Of all 6,766 responses, 1,699 (25.1\%) reported “no concerns"; 652 (9.6\%) of responses were classified as "unspecified or other"; and 322 (4.8\%) did not respond to this survey item.

Responses classified as "unspecified or other” included insufficient information for meaningful codification (e.g. “unknown”; “not sure really”; “I am quite sure there are”) or did not relate to a specific theme. It was often highlighted that digital health alternatives should remain optional ("no concerns as long as it is optional and without penalties"; "these technologies need to be used alongside face-to-face consultations when necessary”; “as long as they do not replace face-to-face consultations!”).

\section{Discussion}

\section{Principal Results}

This study explored patient-perceived benefits and concerns with using remote digital healthcare during the COVID-19 crisis. Patients reported several benefits with digital health services, including ease of access (37.1\%), feeling empowered and informed (23.2\%), improved timeliness of access and treatment (18.6\%), healthcare capacity (11.5\%), and care continuity amidst COVID-19 (7.4\%). In contrast, reported concerns included data security and privacy (17.5\%), clinical uncertainty (17.0\%), the patient-doctor relationship (11.9\%), inequity in access and use (11.8\%), (mis)interpreting information (6.3\%), and digital maturity (3.8\%). Of all 6,766 respondents, 25.1\% reported to have no concerns with digital health services, compared to 3.0\% reporting no benefits. In respondents' free-text descriptions, many further added that digital health services, and in particular remote consultations, are beneficial in some circumstances (e.g. minor conditions; simple check-ups) but should not be at cost of face-to-face options.

\section{Comparison with Prior Work}

\section{Digital health and healthcare access: reducing or widening inequities?}

Our findings mirror current debates regarding the digital divide. In our study, 37.1\% respondents considered digital health services to widen and facilitate accessibility, yet $11.8 \%$ were concerned that 
some patient groups may be left behind. Earlier research has demonstrated that a range of factors, such as access to stable internet[37-39]; language barriers[40,41]; and digital literacy[42,43], that may result in equal access. Some have noted the paradox that those with the lowest health needs (e.g. younger, healthier, and more affluent than average) are most likely to prefer and benefit from digital health[44-46]. Conversely, older persons, and those with lower digital literacy levels, may be particularly underserved[47]. These barriers, which are not randomly distributed across intersections of society, risk creating and perpetuating structural inequities in healthcare access. For this reason, healthcare providers, researchers, designers, and relevant voluntary and community organisations must come together to explore the main barriers and enhancers to access remote and digital care, and find innovative ways to deliver high-quality, patient-centred care that leaves no one behind[48].

Yet, our findings also demonstrate that digital health services improved access for a significant proportion of respondents, who highlighted barriers with regards to travelling and costs for accessing traditional healthcare, including mobility issues, childcare, travel costs, difficulties in taking time off. Out-of-pocket costs for attending outpatient appointments, in particular tertiary care, can be significant for patients[14], and can therefore result in higher non-attendance rates[49,50]. As such, in certain circumstances, digital healthcare alternatives present an important opportunity to increase access and reduce rates of did-not-attends, indicating the need to consider patients and their respective circumstances on both ends of the digital divide, and avoiding a one-size-fits-all approach.

\section{Timeliness, healthcare capacity, and improved triaging}

Timeliness remains a less studied domain of the Institute of Medicine's six domains of high-quality healthcare[51,52], with wider impacts on healthcare poorly understood. Although evidence is somewhat inconsistent, some studies indicate that the introduction of remote consultations can reduce time to initial response[13], time from referral to treatments[11], and, in some cases, timeeffectiveness of consultations[53]. Further, improved triaging based on the nature and urgency of patient conditions (e.g. with minor issues being handled through lower-cost telephone consultations) has also shown to reduce subsequent face-to-face visits in outpatient care[11,12] in some cases. In our study, many patients similarly believed that digital health services had accelerated access and subsequent treatment, and had the potential to support prioritization of health systems resources through improved triaging.

Although these findings suggest potential benefits for the capacity of healthcare systems, some have 
highlighted that 'quick and convenient' access may also increase demand and result in a higher rate of redundant appointments. Further, it must be noted that the potential of digital health to improve whole-systems capacity will partly rely on the relative safety and effectiveness of remote consultations, which thus far remains largely unclear. For example, evidence suggests that telephone consultations are helpful to address minor conditions, but may miss rare but serious conditions, and can result in higher rates of clinical re-attendance[54-56]. As digital health services will increasingly become part of our 'new normal', there is an urgent need for wider evidence across patient groups, clinical conditions, and circumstances to understand if, when, and for whom the digital care services are an effective and safe alternative.

\section{Remote consultations: Clinical effectiveness and the patient-clinician relationship}

Concerns regarding patient-doctor relationship and clinical uncertainty were often discussed in the context of remote consultations, indicating patients are concerned that sub-optimal verbal communication (e.g., 'difficulty in explaining my symptoms'), the limitedness of non-verbal communication, and the absence of physical examination may all result in missed information, lower diagnostic accuracy, and less humane care. This resonates with earlier studies that have found that patients have lower confidence in the safety of remote healthcare due to barriers in reading body language and communicating effectively[57], including fewer opportunities for patients to raise issues[58,59]. Studies exploring healthcare staff' perspectives have similarly demonstrated concerns about the the impacts on patient-staff relationship[60,61] and the loss of personal connection[62], highlighting the need to future research in this area. To date, there has only been a dozen studies examining the impact of video-mediated consultations on patient-professional communication in healthcare, of which only a few in UK-context[63]. Hence, further research is needed that focuses not only on the clinical, but also social and humanistic aspects of virtual alternatives to consultations.

\section{Patient self-service usage of mobile health apps and personal health records}

Our findings reflect both advantages and risks of patient self-service usage of mobile health apps and personal health records. Although a significant proportion reported to feel more empowered and informed by using these tools (23.3\%), there were concerns with self-service usage and (mis)understanding information. In particular, some respondents questioned their ability to correctly 
interpret information provided and were concerned about anxiety and 'knowing too much'. This calls for increased patient education and co-design efforts to ensure that patients are able to understand data about their health (e.g. such as in personal health records), and can distinguish certified health information from non-validated sources. More robust quality assurance and regulatory processes may further be needed as the popularity and usage of mobile health apps continue to grow[64].

\section{Data privacy and the boundaries of healthcare organisations}

Finally, respondents' most reported concern was data security and privacy. Public concerns with the data governance of personal health records have been well-documented, often referring to cybersecurity breaches and commercial third-party end-use as the primary concern[65-67]. Yet, interestingly, respondents in our study also often referred to concerns with government access to personal health data, a potential consequence of recent COVID-19 related initiatives to track personal health data, as well as recent efforts to enable data sharing between governmental bodies and the NHS[68,69]. It is clear that government initiatives such as the UK Memorandum of Understanding, which allows for NHS health data to be shared with the Home Office, are at odds with efforts to increase patient access and usage of digital health services. As digital health solutions will become increasingly integrated into existing healthcare systems, boundaries between health services and third party organisations will need to be protected, with clear regulation around consensual data collection and eventual use

\section{Strengths and limitations}

Strengths of this study include its large sample size, the use of the systematic framework analysis approach to codify a vast number of free-text responses, excellent inter-rater reliability between coders, and the quantification of themes using content analysis to quantitatively characterise patients’ priorities.

Additionally, when compared with primary care, the evaluation of digital healthcare technologies in has been not extensively studied in the context of secondary care, and therefore this study contributes by providing new insights in a less explored area. Finally, another strength is the rich, bottom-up and 'patient-driven' nature of our findings where topics were discussed as prioritized by patients (rather 
than using pre-defined themes).

It is important to note that this study was developed as rapid research to evaluate patients' experiences with using digital health services during the onset of the global pandemic. Data from a non-validated survey was used to examine patient-reported benefits and concerns. The original survey was distributed to patients accessing CIE, which ensured that respondents had first-hand experience with using digital health services (in line with the aim of this study). However, this does mean the sample was not representative of the general population and that views of those unable or unwilling to access digital health services will have been underrepresented. Further, across all 9,359 respondents to the original survey, there were only 6,766 (72.3\%) respondents that completed the open-ended items included in this study. Nearly all of the excluded respondents (98.8\%) did not answer to either the benefits or concerns question, suggesting non-responses were due to respondent fatigue (e.g. rather than the respondents’ particular attitude towards digital health).

The broad nature of the open-ended items means that responses will have been shaped by the respondent's respective experience with particular types of digital health services (e.g. remote consultations, medical records). We have therefore provided details on particular technologies typically referred to by respondents when discussing a particular theme, allowing the interpretation of the results and improving transparency for extrapolation or attempts to do external generalization. Hence, although the coding percentages provide a robustness check in terms of themes being commonly mentioned across the respondent population, frequencies should not be equated with relative priority as perceived by the respondents. It must further be noted that the nature of closeended questions in the original survey may have influenced participants' responses. We have included the full questionnaire in Multimedia Appendix 1.

\section{Conclusions}

Radical changes in how healthcare is accessed and delivered amidst the COVID-19 pandemic have raised a range of new challenges and opportunities for future medical practice. Patients have been at the forefront of trailing these new health technologies and have been able to pinpoint some of the benefits of remote healthcare, as well as highlighting areas of concern. Our study indicates that patients perceive many benefits with digital health services beyond immediate COVID-19 support, such as easier access, feeling empowered and informed, and improved timeliness and treatment, but there are concerns with some aspects of digital healthcare. Some of these include known issues, such 
as unequal access for certain patient groups, risks with data security and privacy, and limited digital maturity. However, other challenges are more fundamental and show that, like clinicians, patients are concerned about the relative clinical uncertainty and wider impacts on their relationship with healthcare providers. Future work is needed for a more in-depth examination of how digital alternatives affect healthcare delivery, access, and patients' experiences of care.

\section{Acknowledgements}

The manuscript was written by JD, ALN, and SG, and reviewed and approved by all authors. JD, AP, NO, and CG contributed to the analysis. SG, ALN, CG, PB, JKQ, AA and NSP developed and launched the questionnaire on Care Information Exchange (CIE). We thank the Imperial College Research Partners Group for their contribution in reviewing a draft of the questionnaire.

\section{Conflicts of Interest}

None declared.

\section{Multimedia Appendix 1}

[insert The digital future of your care questionnaire here]

\section{References}

1. Gunasekeran DV, Tseng RMWW, Tham Y-C, Wong TY. Applications of digital health for public health responses to COVID-19: a systematic scoping review of artificial intelligence, telehealth and related technologies. npj Digital Medicine Nature Publishing Group; 2021;4(1):1-6.

2. WHO. Telemedicine: Opportunities and developments in Member States [Internet]. 2010. Available from: https://www.who.int/goe/publications/goe_telemedicine_2010.pdf

3. Monaghesh E, Hajizadeh A. The role of telehealth during COVID-19 outbreak: a systematic review based on current evidence. BMC Public Health Springer; 2020;20(1):1-9.

4. Ahmed S, Sanghvi K, Yeo D. Telemedicine takes centre stage during COVID-19 pandemic. BMJ Innovations BMJ Specialist Journals; 2020;6(4).

5. Centers for Medicare \& Medicaid Services. President Trump Expands Telehealth Benefits for Medicare Beneficiaries During COVID-19 Outbreak. 2020 Mar 17; Available from: https://www.cms.gov/newsroom/press-releases/president-trump-expands-telehealth-benefitsmedicare-beneficiaries-during-covid-19-outbreak

6. Iyengar K, Jain VK, Vaishya R. Pitfalls in telemedicine consultations in the era of COVID 19 and how to avoid them. Diabetes \& Metabolic Syndrome: Clinical Research \& Reviews Elsevier; 2020;14(5):797-799.

7. OECD. Bringing health care to the patient: An overview of the use of telemedicine in OECD countries [Internet]. 2020 Jan. Report No.: 116. [doi: 10.1787/8e56ede7-en]

8. Ghafur S, Schneider EC. Why Are Health Care Organizations Slow To Adopt Patient-Facing Digital Technologies? Health Affairs, March 2019;6. 
9. Scott Kruse C, Karem P, Shifflett K, Vegi L, Ravi K, Brooks M. Evaluating barriers to adopting telemedicine worldwide: A systematic review. Journal of telemedicine and telecare Sage Publications Sage UK: London, England; 2018;24(1):4-12.

10. Royal College of Physicians. Outpatients: The future - adding value through sustainability [Internet]. 2018 Nov. Available from: https://www.rcplondon.ac.uk/projects/outputs/outpatientsfuture-adding-value-through-sustainability

11. Fox KC, Somes GW, Waters TM. Timeliness and access to healthcare services via telemedicine for adolescents in state correctional facilities. Journal of adolescent health Elsevier; 2007;41(2):161-167.

12. Fisk NM, Sepulveda W, Drysdale K, Ridley D, Garner P, Bower S, Kyle P, Dhillon H, Carvalho JS, Wootton R. Fetal telemedicine: six month pilot of real-time ultrasound and video consultation between the Isle of Wight and London. BJOG: An International Journal of Obstetrics \& Gynaecology Wiley Online Library; 1996;103(11):1092-1095.

13. Kruse CS, Krowski N, Rodriguez B, Tran L, Vela J, Brooks M. Telehealth and patient satisfaction: a systematic review and narrative analysis. BMJ open British Medical Journal Publishing Group; 2017;7(8):e016242.

14. Hommel KA, Hente E, Herzer M, Ingerski LM, Denson LA. Telehealth behavioral treatment for medication nonadherence: a pilot and feasibility study. European journal of gastroenterology \& hepatology NIH Public Access; 2013;25(4):469.

15. Liu X, Varshney U. Mobile health: A carrot and stick intervention to improve medication adherence. Decision Support Systems Elsevier; 2020;128:113165.

16. McGillicuddy JW, Gregoski MJ, Weiland AK, Rock RA, Brunner-Jackson BM, Patel SK, Thomas BS, Taber DJ, Chavin KD, Baliga PK. Mobile health medication adherence and blood pressure control in renal transplant recipients: a proof-of-concept randomized controlled trial. JMIR research protocols JMIR Publications Inc., Toronto, Canada; 2013;2(2):e32.

17. Wu Y, Yao X, Vespasiani G, Nicolucci A, Dong Y, Kwong J, Li L, Sun X, Tian H, Li S. Mobile app-based interventions to support diabetes self-management: a systematic review of randomized controlled trials to identify functions associated with glycemic efficacy. JMIR mHealth and uHealth JMIR Publications Inc., Toronto, Canada; 2017;5(3):e35.

18. Marcolino MS, Oliveira JAQ, D’Agostino M, Ribeiro AL, Alkmim MBM, Novillo-Ortiz D. The impact of mHealth interventions: systematic review of systematic reviews. JMIR mHealth and uHealth JMIR Publications Inc., Toronto, Canada; 2018;6(1):e23.

19. Whitehead L, Seaton P. The effectiveness of self-management mobile phone and tablet apps in long-term condition management: a systematic review. Journal of medical Internet research JMIR Publications Inc., Toronto, Canada; 2016;18(5):e97.

20. Lupton D. Critical perspectives on digital health technologies. Sociology compass Wiley Online Library; 2014;8(12):1344-1359.

21. Fairchild AL, Haghdoost AA, Bayer R, Selgelid MJ, Dawson A, Saxena A, Reis A. Ethics of public health surveillance: new guidelines. The lancet public health Elsevier; 2017;2(8):e348- 
e349.

22. Martinez-Martin N, Char D. Surveillance and digital health. The American journal of bioethics: AJOB NIH Public Access; 2018;18(9):67.

23. Calvo RA, Deterding S, Ryan RM. Health surveillance during covid-19 pandemic. British Medical Journal Publishing Group; 2020;

24. Berg M. Making sense with sensors: Self-tracking and the temporalities of wellbeing. Digital Health SAGE Publications Sage UK: London, England; 2017;3:2055207617699767.

25. Lupton D. Quantified sex: a critical analysis of sexual and reproductive self-tracking using apps. Culture, health \& sexuality Taylor \& Francis; 2015;17(4):440-453.

26. Sharon T. Self-tracking for health and the quantified self: Re-articulating autonomy, solidarity, and authenticity in an age of personalized healthcare. Philosophy \& Technology Springer; 2017;30(1):93-121.

27. Andreassen HK, Trondsen M, Kummervold PE, Gammon D, Hjortdahl P. Patients who use emediated communication with their doctor: new constructions of trust in the patient-doctor relationship. Qualitative health research Sage Publications Sage CA: Thousand Oaks, CA; 2006;16(2):238-248.

28. Husain I, Spence D. Can healthy people benefit from health apps? BmJ British Medical Journal Publishing Group; 2015;350.

29. Wang K, Varma DS, Prosperi M. A systematic review of the effectiveness of mobile apps for monitoring and management of mental health symptoms or disorders. Journal of psychiatric research Elsevier; 2018;107:73-78.

30. Leigh S, Flatt S. App-based psychological interventions: friend or foe? Evidence-based mental health Royal College of Psychiatrists; 2015;18(4):97-99.

31. Nicholas J, Larsen ME, Proudfoot J, Christensen H. Mobile apps for bipolar disorder: a systematic review of features and content quality. Journal of medical Internet research JMIR Publications Inc., Toronto, Canada; 2015;17(8):e198.

32. Srivastava A, Thomson SB. Framework analysis: a qualitative methodology for applied policy research. 2009;

33. Gale NK, Heath G, Cameron E, Rashid S, Redwood S. Using the framework method for the analysis of qualitative data in multi-disciplinary health research. BMC medical research methodology BioMed Central; 2013;13(1):1-8.

34. Gwet K. Kappa statistic is not satisfactory for assessing the extent of agreement between raters. Statistical methods for inter-rater reliability assessment 2002;1(6):1-6.

35. Gwet KL. Computing inter-rater reliability and its variance in the presence of high agreement. British Journal of Mathematical and Statistical Psychology Wiley Online Library; 2008;61(1):29-48.

36. Landis JR, Koch GG. The measurement of observer agreement for categorical data. biometrics 
1977;159-174.

37. Skinner H, Biscope S, Poland B. Quality of internet access: barrier behind internet use statistics. Social Science \& Medicine Elsevier; 2003;57(5):875-880.

38. Rains SA. Health at high speed: Broadband Internet access, health communication, and the digital divide. Communication Research Sage Publications Sage CA: Los Angeles, CA; 2008;35(3):283-297.

39. Townsend L, Salemink K, Wallace CD. Gypsy-Traveller communities in the United Kingdom and the Netherlands: socially and digitally excluded? Media, Culture \& Society SAGE Publications Ltd; 2020 Jul 1;42(5):637-653. [doi: 10.1177/0163443718807381]

40. Talhouk R, Mesmar S, Thieme A, Balaam M, Olivier P, Akik C, Ghattas H. Syrian refugees and digital health in Lebanon: Opportunities for improving antenatal health. 2016. p. 331-342.

41. Nouri S, Khoong EC, Lyles CR, Karliner L. Addressing equity in telemedicine for chronic disease management during the Covid-19 pandemic. NEJM Catalyst Innovations in Care Delivery Massachusetts Medical Society; 2020;1(3).

42. Bodie GD, Dutta MJ. Understanding health literacy for strategic health marketing: eHealth literacy, health disparities, and the digital divide. Health marketing quarterly Taylor \& Francis; 2008;25(1-2):175-203.

43. Chesser A, Burke A, Reyes J, Rohrberg T. Navigating the digital divide: a systematic review of eHealth literacy in underserved populations in the United States. Informatics for Health and Social Care Taylor \& Francis; 2016;41(1):1-19.

44. Rodgers M, Raine GA, Thomas S, Harden M, Eastwood AJ. Informing NHS policy in’digitalfirst primary care': a rapid evidence synthesis. Health Services and Delivery Research York; 2019;1-154.

45. Pearl R. Kaiser Permanente Northern California: current experiences with internet, mobile, and video technologies. Health Affairs 2014;33(2):251-257.

46. Bol N, Helberger N, Weert JC. Differences in mobile health app use: a source of new digital inequalities? The Information Society Taylor \& Francis; 2018;34(3):183-193.

47. Gordon NP, Hornbrook MC. Older adults' readiness to engage with eHealth patient education and self-care resources: A cross-sectional survey. BMC health services research Springer; 2018;18(1):1-13.

48. Neves AL, Lawrence-Jones A, Naar L, Greenfield G, Sanderson F, Hyde T, Wingfield D, Cassidy I, Mayer E. Multidisciplinary teams must work together to co-develop inclusive digital primary care for older people. British Journal of General Practice British Journal of General Practice; 2020;70(701):582-582.

49. Gerlach UA, Vrakas G, Holdaway L, O’Connor M, Macedo R, Reddy S, Friend PJ, Giele H, Vaidya A. Skype clinics after intestinal transplantation-follow-up beyond post codes. Clinical transplantation Wiley Online Library; 2016;30(7):760-766.

50. de Oliveira C, Bremner KE, Ni A, Alibhai SM, Laporte A, Krahn MD. Patient time and out-of- 
pocket costs for long-term prostate cancer survivors in Ontario, Canada. Journal of Cancer Survivorship Springer; 2014;8(1):9-20.

51. Kaplan G, Lopez MH, McGinnis JM. Transforming health care scheduling and access: Getting to now. National Academies Press (US); 2015;

52. Kaplan GS. Health care scheduling and access: a report from the IOM. Jama American Medical Association; 2015;314(14):1449-1450.

53. Nabelsi V, Lévesque-Chouinard A, Liddy C, Pilon MD. Improving the referral process, timeliness, effectiveness, and equity of access to specialist medical services through electronic consultation: pilot study. JMIR medical informatics JMIR Publications Inc., Toronto, Canada; 2019;7(3):e13354.

54. Jones G, Brennan V, Jacques R, Wood H, Dixon S, Radley S. Evaluating the impact of a 'virtual clinic'on patient experience, personal and provider costs of care in urinary incontinence: a randomised controlled trial. PloS one Public Library of Science San Francisco, CA USA; 2018;13(1):e0189174.

55. Newbould J, Abel G, Ball S, Corbett J, Elliott M, Exley J, Martin A, Saunders C, Wilson E, Winpenny E. Evaluation of telephone first approach to demand management in English general practice: observational study. bmj British Medical Journal Publishing Group; 2017;358.

56. Chapman JL, Zechel A, Carter YH, Abbott S. Systematic review of recent innovations in service provision to improve access to primary care. British Journal of General Practice British Journal of General Practice; 2004;54(502):374-381.

57. Petersson NB, Jørgensen AL, Danbjørg DB, Dieperink KB. Video-consulted rounds with caregivers: The experience of patients with cancer. European Journal of Oncology Nursing Elsevier; 2020;46:101763.

58. Roberts L, Osborn-Jenkins L. Delivering remote consultations: Talking the talk. Musculoskeletal Science and Practice Elsevier; 2020;102275.

59. Shaw S, Wherton J, Vijayaraghavan S, Morris J, Bhattacharya S, Hanson P, Campbell-Richards D, Ramoutar S, Collard A, Hodkinson I. Advantages and limitations of virtual online consultations in a NHS acute trust: the VOCAL mixed-methods study. Health Services and Delivery Research National Institute for Health Research; 2018;6(21).

60. Pols J. The heart of the matter. About good nursing and telecare. Health care analysis Springer; 2010;18(4):374-388.

61. Gund A, Sjöqvist BA, Wigert H, Hentz E, Lindecrantz K, Bry K. A randomized controlled study about the use of eHealth in the home health care of premature infants. BMC medical informatics and decision making Springer; 2013;13(1):1-11.

62. Donelan K, Barreto EA, Sossong S, Michael C, Estrada JJ, Cohen AB, Wozniak J, Schwamm LH. Patient and clinician experiences with telehealth for patient follow-up care. Am J Manag Care 2019;25(1):40-44.

63. Shaw SE, Seuren LM, Wherton J, Cameron D, Vijayaraghavan S, Morris J, Bhattacharya S, 
Greenhalgh T. Video consultations between patients and clinicians in diabetes, cancer, and heart failure services: linguistic ethnographic study of video-mediated interaction. Journal of medical Internet research JMIR Publications Inc., Toronto, Canada; 2020;22(5):e18378.

64. Inkster B, O’Brien R, Selby E, Joshi S, Subramanian V, Kadaba M, Schroeder K, Godson S, Comley K, Vollmer SJ. Digital health management during and beyond the COVID-19 pandemic: Opportunities, barriers, and recommendations. JMIR Mental Health JMIR Publications Inc., Toronto, Canada; 2020;7(7):e19246.

65. Ghafur S, Van Dael J, Leis M, Darzi A, Sheikh A. Public perceptions on data sharing: key insights from the UK and the USA. The Lancet Digital Health Elsevier; 2020;2(9):e444-e446.

66. Perera G, Holbrook A, Thabane L, Foster G, Willison DJ. Views on health information sharing and privacy from primary care practices using electronic medical records. International journal of medical informatics Elsevier; 2011;80(2):94-101.

67. Agaku IT, Adisa AO, Ayo-Yusuf OA, Connolly GN. Concern about security and privacy, and perceived control over collection and use of health information are related to withholding of health information from healthcare providers. Journal of the American Medical Informatics Association BMJ Publishing Group BMA House, Tavistock Square, London, WC1H 9JR; 2014;21(2):374-378.

68. Casla K, Roderick P, Pollock AM. Disclosure of patients' data to the UK Home Office must stop. BMJ: British Medical Journal BMJ; 2017;358.

69. Hiam L, Steele S, McKee M. Creating a 'hostile environment for migrants': the British government's use of health service data to restrict immigration is a very bad idea. Health Economics, Policy and Law Cambridge University Press; 2018;13(2):107-117. 


\section{Supplementary Files}




\section{Multimedia Appendixes}

The digital future of your care questionnaire.

URL: http://asset.jmir.pub/assets/af1a1b6f411d3f3112dcd3819fea706e.docx 